\section{Estudo exploratório sobre aleitamento materno entre escolares de quinta série do Ensino Fundamental}

\author{
Exploratory survey of fifth-grade elementary \\ students in relation to breastfeeding
}

\author{
${ }_{1}^{1}$ Departamento de Ciências \\ da Saúde, Universidade \\ Regional do Noroeste do \\ Estado do Rio Grande do Sul, \\ Ijuí, Brasil. \\ 2 Faculdade de Medicina \\ Universidade Federal do Rio \\ Grande do Sul, Porto Alegre, \\ Brasil. \\ Correspondência \\ S. M. Bottaro \\ Departamento de Ciências \\ da Saúde, Universidade \\ Regional do Noroeste do \\ Estado do Rio Grande do Sul. \\ Rua do Comércio 3000 , \\ Ijuí, RS \\ 98700-000, Brasil. \\ silvania@unijui.tche.br
}

\begin{abstract}
The present study assessed the knowledge, perceptions, beliefs, and experiences related to breastfeeding as expressed by 564 fifth-grade students (both boys and girls). A questionnaire was used, containing 25 objective questions. The t test and chi-squared test were used, based on cluster sampling. The students consistently viewed maternal breast milk as the best food for infants, although only 60\% would choose exclusive breastfeeding for their own children. Fewer than 20\% replied that children could be breastfed until two years of age. Approximately one-fourth believed that infants should begin receiving other foods at 6 months of age, and $80 \%$ also believed in the need for tea and water. Other beliefs included: that breast milk is weak or thin; that tea is good for infant colic; that breastfeeding makes the breasts flaccid; that breast size influences the amount of milk; and that breastfeeding should be interrupted as soon as the infant's first teeth appear. They highlighted the importance of the father participating in the breastfeeding process, but $70 \%$ said that the father could help by giving the baby a bottle. There is also an evident need for primary schools to promote measures for a more favorable position towards breastfeeding.
\end{abstract}

Breast Feeding; Health Education; Students
Silvania M. Bottaro 1

Elsa R. J. Giugliani 2

\section{Introdução}

Apesar do aumento progressivo das taxas de aleitamento materno no Brasil nos últimos 25 anos, elas ainda estão muito aquém das recomendadas internacionalmente, ou seja, amamentação por dois anos ou mais, sendo de forma exclusiva nos primeiros seis meses 1 . O último inquérito nacional, realizado em 1999 nas capitais brasileiras e no Distrito Federal, revelou uma duração mediana de amamentação de dez meses, e de amamentação exclusiva de apenas 23 dias 2, o que evidencia a necessidade de esforços adicionais e de novas estratégias para a promoção do aleitamento materno.

Faz-se necessário, então, investir em ações que efetivamente colaborem para a conscientização da importância da amamentação, direcionadas a grupos populacionais específicos, em especial os formadores de opinião. As crianças formam grupo prioritário para esse tipo de ação, pois futuramente se constituirão os sujeitos sociais na luta em defesa da qualidade de vida. Além disso, estudo que investigou estratégias de ensino-aprendizagem baseadas no lúdico para fixação de conceitos e disseminação de informações sobre aleitamento materno em escolares de ambos os sexos do Ensino Fundamental mostrou que as crianças são importante veículo de propagação de informações na sua família e em todo o seu ciclo social 3 . 
Por ser a amamentação uma prática condicionada por fatores sócio-culturais ${ }^{4}$, acredita-se que quanto mais cedo a importância do aleitamento materno for internalizada, mais positiva e favorável a essa prática tornar-se-á ao indivíduo. Assim, parece importante que a promoção do aleitamento materno seja iniciada já na infância. E, a escola, por ser o ambiente institucionalizado do processo pedagógico, poderia contribuir na conscientização das crianças da importância da amamentação. Mas, antes de se instituir qualquer programa nesse sentido, faz-se necessário ter conhecimento prévio da visão dos escolares sobre vários aspectos relacionados à amamentação.

Uma minuciosa revisão da literatura feita nas bases de dados MEDLINE, SciELO, LILACS e Cochrane acusou apenas um estudo brasileiro sobre aleitamento materno, tendo como foco o conhecimento e a opinião de escolares sobre o tema. Esse estudo, realizado em Ribeirão Preto, São Paulo 5, entre escolares de duas escolas do Ensino Fundamental (uma pública e uma privada), revelou que a maioria delas sabe que o leite materno é o melhor alimento para o bebê, mas poucas optariam por amamentar exclusivamente seus filhos. O estudo mostrou, também, que práticas que interferem negativamente na amamentação, tais como o uso de chupeta e o oferecimento de água, chá, sucos e outros leites antes dos seis meses são consideradas normais. Uma limitação deste estudo foi não ter incluído meninos na amostra.

Assim, o presente estudo teve como propósito estudar mais detalhadamente os conhecimentos, as percepções, as crenças e as vivências sobre aleitamento materno de escolares de ambos os sexos do Ensino Fundamental, visando à obtenção de subsídios para a elaboração de programas educativos de incentivo ao aleitamento materno em escolas. Em função da falta de estudos avaliando a visão dos meninos sobre diversos aspectos do aleitamento materno, pouco se sabe se, em função da cultura, os seus conhecimentos, percepções e crenças diferem dos das meninas. Para que o pai possa influenciar positivamente na amamentação, é necessário que ele também assuma uma postura positiva em relação a essa prática. Daí a importância de se conhecer o que os meninos sabem sobre amamentação e como se posicionam em relação a ela. Além disso, sabese que os pais exercem influência na decisão da mulher de amamentar ou não os seus filhos, bem como na duração da amamentação ${ }^{6}$. Pretendese, também, avaliar o quanto dos mitos e das práticas em aleitamento materno vigentes no Brasil é transmitido e captado pelas crianças.

É importante enfatizar que este é um estudo que tem a pretensão de explorar a visão geral de escolares de ambos os sexos sobre diversos aspectos relacionados ao aleitamento materno. O delineamento do estudo não possibilita um maior aprofundamento das questões envolvidas nesta visão. Destaca-se, também, o aspecto inédito deste estudo, uma vez que pesquisas com crianças sobre amamentação são escassas e raramente incluem meninos na investigação.

\section{Metodologia}

Trata-se de um estudo transversal com amostra representativa dos escolares que freqüentam a quinta série das escolas do Ensino Fundamental do Município de Ijuí, Rio Grande do Sul, Brasil, situado a 385km de Porto Alegre, com 78 mil habitantes (68.500 na área urbana e 8.500 na rural). O município conta com 47 escolas diurnas do Ensino Fundamental, sendo 43 públicas (32 em área urbana e 11 em área rural) e quatro particulares (todas em área urbana). Optou-se por estudar os alunos da quinta série porque eles já haviam estudado o corpo humano e a importância da alimentação em geral. As escolas noturnas não foram incluídas no estudo porque a idade dos escolares que freqüentam a quinta série no período noturno é muito superior à média de idade dos alunos do turno diurno. Porém, nos turnos diurnos é possível encontrar alguns alunos cursando a quinta série com idade superior à prevista para matrícula nesta série, considerada entre 10 e 11 anos de idade. Como neste estudo a turma representava o conglomerado, todos os alunos fizeram parte da amostra, mesmo os com idade superior à média.

O cálculo do tamanho da amostra foi realizado considerando-se amostragem por conglomerado em dois estágios, o primeiro tendo como unidade amostral as escolas e o segundo, as turmas de quinta série das escolas sorteadas. Para obter o número de conglomerados necessários estimou-se o efeito do delineamento pela seguinte fórmula: $E D=1+(m-1) p$, onde $m$ corresponde ao número de escolas e $p$ é o coeficiente de correlação intraclasse ?

O cálculo do referido coeficiente foi realizado a partir de estudo-piloto, já que não havia dados disponíveis na literatura. Assim, estimou-se em 24 o número mínimo de conglomerados. Prevendo-se possíveis perdas no decorrer do estudo, ampliou-se o tamanho da amostra em $25 \%$, o que resultou em um total de trinta escolas (19 públicas urbanas, nove públicas rurais e duas particulares). Na primeira etapa da amostragem, foram sorteadas as escolas por meio da geração de números aleatórios, levando-se em consideração a proporção de escolas estaduais, munici- 
pais e particulares, bem como a sua distribuição geográfica: urbana e rural. Na segunda etapa foi sorteada a turma que participaria do estudo.

O instrumento de coleta dos dados, um questionário, elaborado pelas autoras e previamente testado em estudo-piloto, visava à obtenção de dados sobre a escola, o aluno e sua família e continha perguntas que objetivavam avaliar conhecimentos, percepções, crenças e vivências dos escolares em aleitamento materno. Parte das questões foi formulada sob a forma de simulação de um caso, com linguagem adequada para a idade dos alunos, onde eram narradas situações vivenciadas por personagens de uma família, envolvendo um filho recém-nascido. Solicitou-se ao aluno que emitisse sua opinião ou o seu posicionamento em tais situações.

Para avaliar conhecimentos, percepções e crenças, foram elaboradas 25 questões objetivas, abordando os seguintes tópicos: valorização do aleitamento materno (quatro), exclusividade do aleitamento materno nos primeiros seis meses (três), duração do aleitamento materno (uma), freqüência das mamadas (uma), crescimento do bebê amamentado (uma), técnica da amamentação (duas), uso da chupeta (duas), apoio do pai na amamentação (duas), amamentação em mãe que trabalha fora do lar (uma) e crenças referentes ao aleitamento materno (oito). Para cada pergunta objetiva respondida como a opção mais favorável ao aleitamento materno, o aluno recebia um ponto; para as parcialmente favoráveis, ele recebia 0,5 pontos, podendo o escore variar de 0 a 25 pontos. Além de responder as perguntas objetivas, era solicitado ao escolar que citasse três vantagens e três desvantagens da amamentação e da mamadeira, e que ele fizesse sugestões de participação do pai na amamentação.

Para avaliar as vivências prévias das crianças em aleitamento materno, foram considerados os seguintes aspectos: se o escolar fora amamentado; se já havia visto alguém amamentando; e se nas brincadeiras de infância as bonecas mamavam no peito. Ainda foi solicitada a opinião do escolar sobre amamentar em público e sobre como alimentaria seus filhos caso os tivesse agora. O questionário foi respondido individualmente, em sala de aula, na presença dos pesquisadores.

As análises estatísticas incluíram: freqüência absoluta e proporção para descrever as características da amostra estudada; teste de qui-quadrado para verificar a diferença entre proporções; e teste t para amostras independentes comparando médias dos escores. Considerou-se o nível de confiança de $5 \%$ para todos os testes. Os dados foram armazenados no programa Epi Info 6.03 (Centers for Disease Control and Prevention, Atlanta, Estados Unidos) com dupla digitação.
Nas análises estatísticas foi utilizado o programa Stata 8.0 (Stata Corp., College Station, Estados Unidos), que utiliza o efeito de ponderação para amostras por conglomerado. A pesquisa foi aprovada pela Comissão de Pesquisa e Ética do Hospital de Clínicas de Porto Alegre e, posteriormente, pelos órgãos de educação competentes do município e pela direção das escolas. Os pais ou responsáveis pelos alunos assinaram Termo de Consentimento Livre e Esclarecido.

\section{Resultados}

Dos 656 alunos selecionados, 92 (14\%) não participaram do estudo: 41 não trouxeram a autorização do responsável (29 do sexo masculino e 12 do feminino) e 51 se recusaram a participar (36 do sexo masculino e 15 do feminino). Quando comparados os 564 escolares que constituíram a amostra estudada com os 92 escolares não incluídos, pelo teste do qui-quadrado, não houve diferença quanto à idade, sexo, tipo de escola, procedência do aluno e escolaridade dos pais.

A maioria dos escolares tinha entre 9 e 11 anos de idade, 399 (70,7\%), $153(27,1 \%)$ entre 12 e 14 anos e 12 (2,2 \%) de 15 a 17 anos. Houve um leve predomínio de escolares do sexo feminino $(51,1 \%)$. A maioria estudava em escola pública $(87,7 \%)$ e residia em área urbana $(83,7 \%)$. Pouco menos da metade das mães $(46,3 \%)$ e dos pais $(43,5 \%)$ tinha até 8 anos de escolaridade, 159 $(28,1 \%)$ de 9 a 11 anos de estudo e pouco mais de $20 \%$ haviam estudado mais que 12 anos.

A proporção de alunos e alunas que optou pela resposta mais favorável ao aleitamento materno nas diferentes questões encontra-se na Tabela 1. No item "valorização do aleitamento materno", os escolares apresentaram bom desempenho, havendo diferença significativa a favor das alunas na questão sobre a principal função das mamas. Na questão sobre "crescimento do bebê amamentado", aproximadamente $2 / 3$ responderam favoravelmente ao aleitamento materno. Já nos itens "exclusividade do aleitamento materno", "duração da amamentação", "freqüência das mamadas" e "uso de chupetas", menos da metade dos escolares optaram pela resposta mais favorável. Os alunos, mais que as alunas, prefeririam dar colo ao invés de oferecer a chupeta quando o bebê chora. Quanto à técnica de amamentação, a maioria dos escolares respondeu que o bebê precisa aprender a mamar, mas poucos relacionaram trauma mamilar à técnica de amamentação. Quanto à questão sobre o trabalho materno, as alunas, mais que os alunos, relataram acreditar ser possível amamentar mesmo quando a mãe trabalha fora de 
Proporção de escolares do sexo masculino e feminino que optaram pela resposta mais favorável ao aleitamento materno nos diversos tópicos pesquisados nas escolas do Ensino Fundamental. Ijuí, Rio Grande do Sul, Brasil.

\begin{tabular}{|c|c|c|c|c|c|c|c|}
\hline \multirow[t]{2}{*}{ Respostas mais favoráveis ao aleitamento materno } & \multicolumn{2}{|c|}{$\begin{array}{l}\text { Masculino } \\
(n=281)\end{array}$} & \multicolumn{2}{|c|}{$\begin{array}{l}\text { Feminino } \\
(n=283)\end{array}$} & \multicolumn{2}{|c|}{$\begin{array}{c}\text { Total } \\
(\mathrm{N}=564)\end{array}$} & \multirow[t]{2}{*}{$p^{* *}$} \\
\hline & $\mathbf{n}$ & $\%$ * & $\mathbf{n}$ & $\%$ * & $\mathbf{n}$ & $\%$ * & \\
\hline \multicolumn{8}{|l|}{ Valorização do aleitamento materno } \\
\hline \multicolumn{8}{|l|}{ A principal função das mamas é dar de mamar para crianças } \\
\hline pequenas & 219 & 88,4 & 243 & 94,8 & 462 & 91,7 & 0,021 \\
\hline O leite do peito da mãe é o melhor leite para o bebê & 257 & 92,1 & 272 & 96,8 & 529 & 94,5 & 0,054 \\
\hline \multicolumn{8}{|l|}{ Se fosse médico aconselharia a mãe a dar só o peito para o } \\
\hline recém-nascido & 179 & 70,8 & 208 & 77,4 & 387 & 74,3 & 0,110 \\
\hline As crianças que mamam no peito pegam menos doenças & 219 & 93,1 & 226 & 95,2 & 445 & 94,2 & 0,347 \\
\hline \multicolumn{8}{|l|}{ Exclusividade do aleitamento materno nos primeiros seis meses } \\
\hline \multicolumn{8}{|l|}{ Bebê com 15 dias que mama só no peito não precisa } \\
\hline receber água e chá & 60 & 24,7 & 62 & 23,9 & 122 & 24,3 & 0,863 \\
\hline \multicolumn{8}{|l|}{ Bebê deve começar a receber outros alimentos em torno } \\
\hline dos seis meses & 64 & 25,2 & 73 & 28,4 & 137 & 26,8 & 0,593 \\
\hline \multicolumn{8}{|l|}{ O bebê que mama só no peito não precisa tomar água ou } \\
\hline chá entre as mamadas & 89 & 41,0 & 86 & 38,2 & 175 & 39,5 & 0,559 \\
\hline \multicolumn{8}{|l|}{ Duração da amamentação } \\
\hline A criança pode mamar dois anos ou mais & 43 & 15,6 & 58 & 20,0 & 101 & 17,9 & 0,169 \\
\hline \multicolumn{8}{|l|}{ Freqüência das mamadas } \\
\hline Bebê pequeno não tem horário para mamar várias vezes ao dia & 132 & 52,8 & 126 & 47,0 & 258 & 49,8 & 0,155 \\
\hline \multicolumn{8}{|l|}{ Crescimento do bebê amamentado } \\
\hline \multicolumn{8}{|l|}{ Bebê que mama só no peito nos seis primeiros meses fica com } \\
\hline o peso adequado & 151 & 62,2 & 160 & 65,8 & 311 & 64,1 & 0,547 \\
\hline \multicolumn{8}{|l|}{ Técnica de amamentação } \\
\hline Bebê machuca o peito da mãe porque está mamando de mau jeito & 69 & 29,5 & 70 & 26,6 & 139 & 28,0 & 0,490 \\
\hline O bebê precisa aprender a mamar & 151 & 64,8 & 175 & 67,0 & 326 & 66,0 & 0,471 \\
\hline \multicolumn{8}{|l|}{ Uso da chupeta } \\
\hline Dar colo para o bebê que chora é melhor do que dar o bico & 101 & 40,1 & 72 & 28,2 & 173 & 33,9 & 0,036 \\
\hline \multicolumn{8}{|l|}{ Na maioria das vezes não é preciso oferecer bico para acalmar o } \\
\hline bebê & 75 & 31,6 & 100 & 37,6 & 175 & 34,7 & 0,183 \\
\hline \multicolumn{8}{|l|}{ Mãe que trabalha } \\
\hline É possível a mãe trabalhar fora de casa e continuar amamentando & 134 & 56,8 & 162 & 64,0 & 296 & 60,5 & 0,039 \\
\hline \multicolumn{8}{|l|}{ Apoio do pai na amamentação } \\
\hline A melhor maneira de o pai ajudar para que a amamentação seja & & & & & & & \\
\hline boa é dando força & 116 & 48,6 & 139 & 55,1 & 255 & 52,2 & 0,173 \\
\hline É muito importante a participação do pai para que a mulher & & & & & & & \\
\hline amamente com sucesso & 233 & 91,0 & 247 & 92,3 & 480 & 91,7 & 0,664 \\
\hline Crenças & & & & & & & \\
\hline O bebê gosta mais do peito do que da mamadeira & 253 & 93,0 & 269 & 97,1 & 522 & 95,1 & 0,083 \\
\hline É mais fácil amamentar um bebê dando o peito do que a mamadeira & 188 & 70,6 & 194 & 73,1 & 382 & 71,9 & 0,570 \\
\hline Amamentar não dói & 156 & 85,3 & 148 & 80,3 & 304 & 82,7 & 0,295 \\
\hline Leite do peito não é fraco & 100 & 42,5 & 113 & 44,9 & 213 & 43,4 & 0,498 \\
\hline A mulher que tem mamas grandes produz a mesma quantidade & & & & & & & \\
\hline de leite que a mulher com mamas pequenas & 92 & 40,5 & 94 & 41,0 & 86 & 40,7 & 0,926 \\
\hline A mãe precisa parar de dar o peito para o bebê quando ele & & & & & & & \\
\hline começa a dentição & 118 & 49,3 & 136 & 54,6 & 254 & 52,1 & 0,335 \\
\hline O bebê que tem cólicas ou chora muito não precisa de chá & 36 & 14,8 & 23 & 8,8 & 59 & 11,6 & 0,093 \\
\hline A amamentação não é a principal causa do peito caído & 58 & 31,3 & 93 & 43,2 & 151 & 37,7 & 0,020 \\
\hline
\end{tabular}

* Os percentuais não correspondem aos valores esperados em relação à freqüência absoluta devido à ponderação aplicada por tratar-se de amostra por conglomerado;

** Teste de qui-quadrado. 
casa. Foi quase consenso entre os alunos que a participação do pai na amamentação é importante. No entanto, apenas metade achava que a melhor maneira de o pai ajudar na amamentação era apoiando essa prática.

As crenças relacionadas ao aleitamento materno, freqüentemente relatadas foram: existe leite fraco, o volume de leite está relacionado com o tamanho das mamas, chá é bom para cólicas, a amamentação deixa o peito caído (mais evidente entre os meninos) e a amamentação deve ser interrompida com o aparecimento dos dentes.

A Tabela 2 mostra as vivências prévias dos alunos e alunas em relação ao aleitamento materno, assim como a opinião sobre amamentar em público e a escolha do método de alimentação para os seus filhos. A maioria diz ter sido amamentada e que já presenciou alguém amamentando. Porém, nas brincadeiras de infância, menos da metade dos escolares do sexo feminino e poucos do sexo masculino relataram que as bonecas eram amamentadas. A maioria dos escolares, em especial os do sexo feminino, não tem restrição quanto à amamentação em público. Quando questionados sobre como gostariam que seu filho fosse alimentado futuramente, aproximadamente $60 \%$ responderam que gostariam que fosse com o leite materno.

A Tabela 3 apresenta as médias dos escores obtidos no teste sobre conhecimentos, percepções e crenças em aleitamento materno, de acordo com algumas características da amostra. A comparação das médias revelou que os escolares do sexo feminino, os que relataram ter sido amamentados, os que vivenciaram brincadeiras com bonecas amamentadas, os que não tinham restrição quanto à amamentação em público e os que gostariam que os seus filhos fossem amamentados exclusivamente obtiveram os maiores escores. Não houve diferença quanto à idade do escolar, tipo de escola e escolaridade dos pais.

A Tabela 4 lista as respostas dadas pelos dois sexos quando solicitados a citar três vantagens e três desvantagens da amamentação e da ma-

Vivências prévias em aleitamento materno, intenção de terem seus filhos amamentados e opinião sobre amamentação em público de escolares do sexo masculino e feminino da quinta-série do Ensino Fundamental. ljuí, Rio Grande do Sul, Brasil.

\begin{tabular}{|c|c|c|c|c|c|c|c|}
\hline \multirow[t]{2}{*}{ Respostas mais favoráveis ao aleitamento materno } & \multicolumn{2}{|c|}{$\begin{array}{l}\text { Masculino } \\
(n=281)\end{array}$} & \multicolumn{2}{|c|}{$\begin{array}{l}\text { Feminino } \\
(n=283)\end{array}$} & \multicolumn{2}{|c|}{$\begin{array}{c}\text { Total } \\
(\mathrm{N}=564)\end{array}$} & \multirow[t]{2}{*}{$p * *$} \\
\hline & $\mathrm{n}$ & $\%$ * & $\mathrm{n}$ & $\%$ * & $\mathrm{n}$ & $\%$ * & \\
\hline \multicolumn{8}{|l|}{ Escolar foi amamentado } \\
\hline $\operatorname{Sim}$ & 263 & 93,4 & 264 & 92,8 & 527 & 93,1 & 0,862 \\
\hline Não & 9 & 3,1 & 10 & 3,9 & 19 & 3,5 & \\
\hline Não sabe & 9 & 3,5 & 9 & 3,3 & 18 & 3,4 & \\
\hline \multicolumn{8}{|l|}{ Viu alguém amamentando } \\
\hline Sim & 270 & 97,9 & 280 & 98,9 & 550 & 98,4 & 0,264 \\
\hline Não & 5 & 2,1 & 3 & 1,1 & 8 & 1,5 & \\
\hline \multicolumn{8}{|l|}{ Nas brincadeiras de infância, as bonecas mamavam no peito } \\
\hline Sim & 44 & 16,6 & 114 & 41,7 & 158 & 29,4 & $<0,001$ \\
\hline Não & 136 & 45,9 & 161 & 55,7 & 297 & 50,9 & \\
\hline Não sabe & 101 & 37,5 & 8 & 2,6 & 109 & 19,7 & \\
\hline \multicolumn{8}{|c|}{ Acha feio dar o peito para o bebê na frente de outras pessoas } \\
\hline Sim & 50 & 18,6 & 29 & 9,8 & 79 & 14,1 & $<0,001$ \\
\hline Não & 203 & 70,7 & 241 & 85,2 & 444 & 78,1 & \\
\hline Não sabe & 28 & 10,7 & 13 & 5,0 & 41 & 7,8 & \\
\hline \multicolumn{8}{|l|}{ Como alimentaria seus próprios filhos } \\
\hline Só com leite do peito & 167 & 60,6 & 171 & 61,7 & 338 & 61,1 & 0,611 \\
\hline Só com leite em pó ou de vaca na mamadeira & 15 & 5,4 & 14 & 4,1 & 29 & 4,7 & \\
\hline Com leite do peito e outro leite na mamadeira & 52 & 16,7 & 56 & 19,7 & 108 & 18,2 & \\
\hline Não tem opinião & 47 & 17,3 & 42 & 15,6 & 89 & 15,9 & \\
\hline
\end{tabular}

* Os percentuais não correspondem aos valores esperados em relação à freqüência absoluta devido à ponderação aplicada por tratar-se de amostra por conglomerado;

** Teste de qui-quadrado. 
Desempenho dos escolares na avaliação de conhecimentos, percepções e crenças relacionadas ao aleitamento materno, de acordo com características selecionadas. ljuí, Rio Grande do Sul, Brasil.

\begin{tabular}{|c|c|c|}
\hline Variáveis & Escore & $p$ * \\
\hline & Média \pm erro padrão & \\
\hline \multicolumn{3}{|l|}{ Sexo } \\
\hline Masculino & $12,2 \pm 0,29$ & 0,021 \\
\hline Feminino & $12,9 \pm 0,33$ & \\
\hline \multicolumn{3}{|l|}{ Idade (anos) } \\
\hline 9-11 & $12,7 \pm 0,32$ & 0,073 \\
\hline $12-17$ & $12,1 \pm 0,28$ & \\
\hline \multicolumn{3}{|l|}{ Tipo de escola } \\
\hline Pública & $12,5 \pm 0,19$ & 0,723 \\
\hline Privada & $13,1 \pm 1,72$ & \\
\hline \multicolumn{3}{|l|}{ Procedência } \\
\hline Urbana & $12,6 \pm 0,30$ & 0,828 \\
\hline Rural & $12,5 \pm 0,30$ & \\
\hline \multicolumn{3}{|l|}{ Mamou no peito } \\
\hline $\operatorname{Sim}$ & $12,7 \pm 0,28$ & 0,005 \\
\hline Não/Não sabe & $11,2 \pm 0,52$ & \\
\hline \multicolumn{3}{|c|}{ Vivenciou brincadeiras na infância com bonecas que mamavam no peito } \\
\hline $\operatorname{Sim}$ & $13,3 \pm 0,30$ & 0,010 \\
\hline Não/Não sabe & $12,7 \pm 0,30$ & \\
\hline \multicolumn{3}{|c|}{ Acha feio amamentar em público } \\
\hline Não & $12,6 \pm 0,28$ & $<0,001$ \\
\hline Sim/Não sabe & $11,2 \pm 0,34$ & \\
\hline \multicolumn{3}{|c|}{ Método de alimentação preferencial para os filhos } \\
\hline Só com leite do peito & $13,6 \pm 0,29$ & $<0,001$ \\
\hline Outro leite na mamadeira & $10,8 \pm 0,24$ & \\
\hline \multicolumn{3}{|l|}{ Escolaridade da mãe (anos) } \\
\hline Até 8 & $13,0 \pm 0,20$ & 0,910 \\
\hline Mais de 8 & $13,1 \pm 0,53$ & \\
\hline \multicolumn{3}{|l|}{ Escolaridade do pai (anos) } \\
\hline Até 8 & $12,8 \pm 0,25$ & 0,089 \\
\hline Mais de 8 & $13,5 \pm 0,39$ & \\
\hline
\end{tabular}

* Teste t para amostras independentes.

madeira, e a dizer como o pai pode participar na amamentação. $\mathrm{O}$ aspecto favorável mais citado da amamentação foi que o leite materno é o melhor alimento. A maioria relatou não haver aspectos negativos na amamentação. O aspecto positivo da mamadeira mais enfatizado foi a sua praticidade, e o negativo, a dificuldade de conservá-la limpa. Quando questionados sobre como o pai poderia ajudar na amamentação, dar mamadeira para a criança foi a resposta mais comum entre os escolares de ambos os sexos.

\section{Discussão}

Julgamos ser importante conhecer a visão da criança, independentemente do sexo, sobre vários aspectos do aleitamento materno. Esse conhecimento pode nortear o trabalho das escolas do Ensino Fundamental no sentido de esclarecer e conscientizar os seus alunos sobre a importância da amamentação. Este estudo trouxe subsídios que ampliam o nosso conhecimento sobre o grau de informação em aleitamento materno do aluno de quinta série e as suas percepções e crenças sobre o tema. Ele teve o mérito de abordar, também, a visão dos escolares do sexo masculino, tópico ainda não explorado na literatura 
Respostas das perguntas descritivas sobre três vantagens e três desvantagens da amamentação e da mamadeira e sugestões sobre a participação do pai na amamentação, pelos escolares do sexo masculino e feminino da quinta-série das escolas do Ensino Fundamental. ljuí, Rio Grande do Sul, Brasil.

\begin{tabular}{|c|c|c|c|c|c|}
\hline \multirow[t]{2}{*}{ Variáveis } & \multicolumn{2}{|c|}{$\begin{array}{c}\text { Masculino } \\
(n=281)\end{array}$} & \multicolumn{2}{|c|}{$\begin{array}{l}\text { Feminino } \\
(n=283)\end{array}$} & \multirow[t]{2}{*}{$p$ * } \\
\hline & $\mathrm{n}$ & $\%$ & $\mathrm{n}$ & $\%$ & \\
\hline \multicolumn{6}{|l|}{ Vantagens da amamentação } \\
\hline Leite materno é o melhor alimento & 279 & 99,3 & 204 & 72,1 & $<0,001$ \\
\hline Evita doenças & 167 & 59,4 & 181 & 64,0 & \\
\hline É prático & 104 & 37,0 & 117 & 41,4 & \\
\hline É nutritivo & 88 & 31,4 & 104 & 36,8 & \\
\hline Deixa o bebê mais inteligente & 35 & 12,5 & 46 & 16,3 & \\
\hline É bom sob o ponto de vista psicológico & 28 & 10,0 & 28 & 9,9 & \\
\hline É econômico & 26 & 9,3 & 56 & 19,8 & \\
\hline Outras & 116 & 41,2 & 113 & 39,9 & \\
\hline \multicolumn{6}{|l|}{ Desvantagens da amamentação } \\
\hline Não há & 267 & 95,1 & 235 & 83,1 & 0,046 \\
\hline Não é prática & 111 & 39,5 & 130 & 45,9 & \\
\hline O peito fica caído & 98 & 34,9 & 85 & 30,0 & \\
\hline O bebê morde o seio da mãe & 45 & 16,1 & 40 & 14,1 & \\
\hline Em alguns lugares é constrangedor amamentar & 28 & 10,0 & 46 & 16,2 & \\
\hline Quando a mãe fuma e/ou bebe & 23 & 8,2 & 38 & 13,4 & \\
\hline Outras & 271 & 96,4 & 275 & 97,1 & \\
\hline \multicolumn{6}{|l|}{ Vantagens da mamadeira } \\
\hline É nutritivo & 259 & 92,1 & 270 & 95,4 & 0,041 \\
\hline É prático & 245 & 87,2 & 248 & 87,6 & \\
\hline Ajuda no desmame & 75 & 26,7 & 89 & 31,4 & \\
\hline Não machuca o peito & 73 & 26,0 & 88 & 31,0 & \\
\hline Acostuma com outro tipo de comida & 35 & 12,5 & 44 & 15,6 & \\
\hline Outros & 156 & 55,5 & 110 & 38,9 & \\
\hline \multicolumn{6}{|l|}{ Desvantagens da mamadeira } \\
\hline Suja facilmente e é ruim de limpar & 190 & 67,6 & 180 & 63,6 & $<0,001$ \\
\hline Deixa os dentes tortos & 131 & 46,6 & 104 & 36,8 & \\
\hline O bico tem gosto ruim & 105 & 37,3 & 87 & 30,7 & \\
\hline Criança fica doente & 88 & 31,3 & 76 & 26,9 & \\
\hline Não é nutritivo & 78 & 27,8 & 64 & 22,6 & \\
\hline Difícil de largar & 59 & 21,0 & 55 & 19,4 & \\
\hline A criança sente falta da mãe & 58 & 20,6 & 64 & 22,6 & \\
\hline Outros & 134 & 47,7 & 219 & 77,4 & \\
\hline \multicolumn{6}{|l|}{ Participação do pai na amamentação } \\
\hline Dando mamadeira & 249 & 88,6 & 185 & 65,3 & 0,005 \\
\hline Dando apoio na hora da mãe amamentar & 148 & 52,7 & 176 & 62,1 & \\
\hline Ajudando a mulher nos afazeres domésticos & 139 & 49,5 & 156 & 55,1 & \\
\hline Dando amor e carinho para o bebê e a mãe & 41 & 14,6 & 54 & 19,0 & \\
\hline Outros & 266 & 94,6 & 278 & 98,2 & \\
\hline
\end{tabular}

* Significância em relação ao teste qui-quadrado.

médica. Os dados aqui apresentados seguramente podem ser generalizados para a população que costuma freqüentar a quinta série do Ensino Fundamental do município em que o estudo foi desenvolvido, graças à cuidadosa seleção da amostra. Possivelmente, podem ser generaliza- dos também para populações brasileiras com características semelhantes às do presente estudo. Infelizmente, a escassez de pesquisas com o mesmo objetivo do presente trabalho limitam as comparações com outras populações de escolares na faixa etária estudada. 
Os resultados mostram que os escolares referem ser o aleitamento materno importante, porém precisam ser melhor informados sobre vários aspectos. A valorização da amamentação foi o tópico em que houve os melhores escores, e o leite materno foi apontado como o melhor alimento, havendo dificuldade em apontar aspectos negativos da amamentação. Em Ribeirão Preto, as alunas de quarta a oitava série também consideraram o leite materno o melhor alimento para o bebê, apesar de desconhecerem suas vantagens específicas 5 . A valorização do aleitamento materno entre os escolares provavelmente reflete a opinião dos adultos. Estudos brasileiros com mulheres adultas têm demonstrado que elas possuem um alto grau de conhecimento com relação às vantagens do aleitamento materno, apesar de desconhecerem alguns aspectos importantes para a manutenção do aleitamento materno exclusivo por seis meses e complementado por dois anos ou mais 8,9. O mesmo pode ser observado entre os escolares estudados, pois, apesar de valorizarem a amamentação, pouco sabem sobre outros aspectos dessa prática, como duração recomendada, época da introdução de outros alimentos, freqüência das mamadas e técnica de amamentação. Menos de $20 \%$ dos escolares responderam que a criança pode mamar até dois anos ou mais, aproximadamente $1 / 4$ acredita que a criança deve começar a receber outros alimentos em torno dos seis meses, e a maioria pensa ser necessário o uso de chás e água em crianças amamentadas. O nível de informação dos escolares nesses aspectos se mostrou coerente com o que ocorre na prática. A Pesquisa Nacional sobre Prevalência de Aleitamento Materno no Brasil revela que menos da metade das crianças de 9 a 12 meses que residem nas capitais do país é amamentada, que menos de $10 \%$ das com 5 a 6 meses recebem leite materno exclusivamente e que $1 / 4$ recebe água e/ou chá já no primeiro mês de vida 2 .

Da mesma maneira, a opinião dos escolares sobre a necessidade do uso da chupeta coincide com a prática, tão arraigada em nosso meio. Mais da metade das crianças brasileiras menores de um ano usa chupeta ${ }^{2}$. A percepção de que água, chás e chupeta devem ser ofertados precocemente aos bebês também foi constatada entre as escolares de Ribeirão Preto 5 .

O presente estudo revelou que algumas crenças antigas que interferem negativamente na prática do aleitamento materno estão sendo transmitidas de geração a geração, como a existência de leite fraco, a associação entre tamanho de mama e capacidade de produção de leite e o uso de chá para o manejo das cólicas. É possível que a freqüência com que as crianças assistem a mulheres que amamentam oferecendo outros leites para saciar a fome dos seus bebês faça com que elas acreditem que exista leite fraco. $\mathrm{O}$ mesmo ocorre com a crença de que chá seja remédio para cólica do bebê, já que essa prática é bastante arraigada na cultura brasileira 10,11 , mesmo entre os pediatras. Em Pelotas, Rio Grande do Sul, 44\% dos 150 médicos entrevistados que prestavam atendimento a crianças recomendavam uso de chás para lactentes abaixo de seis meses para tratamento de cólicas, suplementação à dieta e reidratação oral 11,12. As mulheres e os homens, portanto, ao se tornarem pais, já vêm com idéias pré-concebidas, desde a infância, quanto à alimentação da criança. Daí a importância da escola em contribuir para a desmistificação de algumas percepções e crenças que interferem negativamente na prática do aleitamento materno.

Esta pesquisa incluiu os alunos do sexo masculino pela importância do apoio do pai para uma amamentação bem sucedida 6 . Inclusive os escolares investigados foram quase unânimes em afirmar que a participação do pai é muito importante, muito embora tivessem dificuldade em especificar como ele poderia ajudar na amamentação. Ao incluir os meninos, o estudo revelou alguns aspectos até então desconhecidos. Observou-se, por exemplo, que o conhecimento dos escolares do sexo masculino não difere muito do sexo feminino em muitos aspectos, apesar de a média do desempenho das meninas ter sido significativamente maior que a dos meninos (a diferença da média dos escores equivale a apenas uma questão). Os alunos, assim como as alunas, valorizam o aleitamento materno, mas desconhecem muitos aspectos dessa prática e possuem basicamente as mesmas crenças. As diferenças das repostas encontradas entre os sexos estão, muitas delas, relacionadas ao papel sexual das mamas. Os escolares do sexo masculino, com mais freqüência, não consideraram a amamentação a principal função das mamas e opinaram negativamente sobre a amamentação em público, bem como acreditam que essa prática é a principal causa do peito caído. O fato de os meninos acreditarem menos que as meninas que é possível a mãe trabalhar fora e amamentar pode ser um indício da vigência de padrões conservadores em relação à divisão sexual do trabalho em nosso meio. Portanto, parece haver a existência de tabus que devem ser considerados ao se promover a amamentação entre crianças e adolescentes, em especial entre os do sexo masculino. Além disso, o entendimento da amamentação como responsabilidade feminina tem levado o homem a manter-se afastado, envolvendo-se pouco no processo, com conseqüente sentimento de exclusão 13,14. A inclusão 
de meninos em programas de incentivo ao aleitamento materno na escola poderia minimizar essa problemática.

Ao se pesquisar as vivências prévias dos escolares em aleitamento materno, pretendia-se avaliar a influência dessas vivências no seu posicionamento quanto a esta prática e também o nível de exposição das crianças à mamadeira através de brincadeiras. O estudo mostrou que os escolares, em sua grande maioria, foram amamentados e são expostos ao ato de amamentar. Porém, menos de metade das alunas relataram ter tido a vivência de amamentar as suas bonecas e menos de $20 \%$ dos estudantes do sexo masculino participaram de brincadeiras em que as bonecas eram amamentadas. Esse fato, também observado entre as meninas de Ribeirão Preto ${ }^{5}$, reflete a "cultura histórica da mamadeira", tão bem representada pelas bonecas acompanhadas de mamadeiras e chupetas. É interessante observar que as crianças com vivências mais positivas quanto ao aleitamento materno (foram amamentadas e vivenciaram brincadeiras com bonecas amamentadas) mostraram posicionamento mais positivo à prática (obtiveram escores significativamente mais altos).

Este estudo revelou algumas contradições, possivelmente as mesmas encontradas entre os adultos. Apesar de os escolares considerarem o leite materno o melhor alimento para o bebê, o mito do leite fraco está presente e apenas $60 \%$ deles optariam pela amamentação exclusiva como método de alimentação preferencial pa- ra os seus próprios filhos. Outra contradição diz respeito ao pai que, apesar de ser considerado muito importante para o sucesso do aleitamento materno, é visto como a pessoa que pode ajudar oferecendo mamadeira à criança.

Se por um lado houve contradições, por outro os escolares foram coerentes em um aspecto importante: os que optariam por dar somente leite materno aos seus filhos tiveram um melhor desempenho na avaliação, ou seja, posicionaramse mais favoravelmente em relação aos vários aspectos da amamentação e práticas relacionadas.

Concluindo, este estudo mostrou que os escolares valorizam o aleitamento materno, mas têm poucos conhecimentos e algumas percepções e crenças negativas com relação a essa prática. Os alunos do sexo masculino tiveram uma visão do aleitamento materno semelhante à do sexo feminino, diferindo em algumas questões, principalmente relacionadas à mama como órgão sexual. Ficou evidente que os conhecimentos, as percepções e as crenças dos escolares são reflexos do que é comumente praticado, como o consumo precoce de chás e o uso da mamadeira, chupeta e outros leites. Essas informações são importantes, e devem ser levadas em consideração na elaboração de estratégias de promoção do aleitamento materno entre os escolares do ensino fundamental. A falta de informações importantes sobre aleitamento materno e aspectos relacionados evidenciada neste estudo aponta para a necessidade de inclusão do tema no currículo escolar.

\section{Resumo}

O estudo avaliou conhecimentos, percepções, crenças e vivências em relação ao aleitamento materno em 564 escolares, de ambos os sexos, da quinta série do Ensino Fundamental. O questionário usado continha 25 questões objetivas. Aplicou-se o teste de qui-quadrado e teste $t$, considerando a amostragem por conglomerado. Os escolares consideraram o leite materno o melhor alimento para o bebê, mas $60 \%$ optariam pela amamentação exclusiva de seus filhos. Menos de $20 \%$ responderam que a criança pode mamar até dois anos ou mais, aproximadamente $1 / 4$ acredita que o bebê deve começar a receber outros alimentos aos seis meses, $e$ mais de 80\% acredita que o consumo de chás e água é necessário. Detectaram-se as seguintes crenças: existência de leite fraco, chá é bom para cólicas, a amamentação deixa o peito caído, tamanho da mama influencia no volume de leite e a lactação deve ser interrompida com o aparecimento dos dentes. Destacaram também a participação do pai na amamentação, porém $70 \%$ relataram que ele pode ajudar dando mamadeira. Evidencia-se a necessidade de ações que promovam uma postura mais favorável à amamentação no Ensino Fundamental.

Aleitamento Materno; Educação em Saúde; Estudantes 


\section{Colaboradores}

S. M. Bottaro contribuiu na revisão de literatura, elaboração da metodologia, análise dos resultados e redação do artigo final. E. R. J. Giugliani colaborou na revisão da literatura, análise dos resultados e redação do artigo final.

\section{Referências}

1. Kramer MS, Kakuma R. Optimal duration of exclusive breastfeeding. In: The Cochrane Library, Issue 1, 2002. Oxford: Update Software.

2. Área de Saúde da Criança, Secretaria de Políticas de Saúde, Ministério da Saúde. Prevalência de aleitamento materno nas capitais brasileiras e no Distrito Federal. Brasília: Ministério da Saúde; 2001.

3. Almeida JAG. Amamentação: um híbrido naturezacultura. J Pediatr (Rio J) 2004; 80(5 Suppl):S119-25.

4. Terrengui LCS. Avaliação de um programa educativo sobre amamentação aplicado a escolares do ensino fundamental [Dissertação de Mestrado]. São Paulo: Universidade de Santo Amaro; 2003.

5. Nakamura SS, Veiga KF, Ferrarese SRB, Martinez FE. Percepção e conhecimento de meninas escolares sobre o aleitamento materno. J Pediatr (Rio J) 2003; 79:181-8.

6. Bar-Yam NB, Darby L. Fathers and breastfeeding: a review of the literature. J Hum Lact 1997; 13:45-50.

7. Ukoumunne OC, Gulliford MC, Chinn S, Sterne JA, Burney PG, Donner A. Methods in health service research. Evaluation of health interventions at area and organisation level. BMJ 1999; 319:376-9.

8. Giugliani ERJ, Rocha VL, Neves JM, Polanczyk CA, Seffrin CF, Susin LO. Conhecimentos maternos em amamentação e fatores associados. J Pediatr (Rio J) $1995 ; 71: 77-81$
9. Susin LRO, Giugliani ERJ, Kummer SC, Maciel M, Benjamin ACW, Machado DB, et al. Uma estratégia simples que aumenta os conhecimentos das mães em aleitamento materno e melhora as taxas de amamentação. J Pediatr (Rio J) 1998; 74:368-75.

10. Vieira GO, Silva LR, Vieira TO, Almeida JAG, Cabral VA. Hábitos alimentares de crianças menores de 1 ano amamentadas e não-amamentadas. J Pediatr (Rio J) 2004; 80:411-6.

11. Marques NM, Lira PIC, Lima MC, Silva NL, Batista Filho M, Huttly SRA, et al. Breastfeeding and early weaning practices in northeast Brazil: a longitudinal study. Pediatrics 2001; 108:E66.

12. Cesar JA, Kuhn D, Devens ES, Martins Jr. E, Aguiar MR, Holthausen RS, et al. Prescrição de chás para crianças menores de seis meses: a opinião dos médicos de uma cidade de porte médio no Sul do Brasil. J Pediatr (Rio J) 1996; 72:27-31.

13. Jordan PL, Wall VR. Supporting the father when an infant is breastfed. J Hum Lact 1993; 9:31-4.

14. Susin LRO. Influência do pai e das avós no aleitamento materno [Tese de Doutorado]. Porto Alegre: Universidade Federal do Rio Grande do Sul; 2003.

Recebido em 31/Ago/2006

Versão final reapresentada em 26/Jun/2007 Aprovado em 30/Nov/2007 